\title{
Article \\ A Balkan View on the Left Periphery: Modal and Discourse Particles
}

\author{
Anna Roussou
}

check for

updates

Citation: Roussou, Anna. 2021. A Balkan View on the Left Periphery: Modal and Discourse Particles.

Languages 6: 75. https://doi.org/ 10.3390/languages6020075

Academic Editors: Ángel Gallego, Bruno Camus, Ricardo Etxepare,

Iván Ortega-Santos, Diego Pescarini, Francesc Roca, Juan Uriagereka and Greta Mazzaggio

Received: 8 February 2021

Accepted: 12 April 2021

Published: 15 April 2021

Publisher's Note: MDPI stays neutral with regard to jurisdictional claims in published maps and institutional affiliations.
Department of Philology, University of Patras, 26504 Rion Patras, Greece; aroussou@upatras.gr

\begin{abstract}
The present paper discusses two sets of so-called particles in the Balkan languages, arguing that the correspondences attested in the E-languages reveal abstract properties at the level of the I-language. The first set involves modal particles which participate in the analytic expressions of the "future" and the "subjunctive". Future markers are construed as V-related elements externalizing a scope position of the verb, while the subjunctive markers take their features from the nominal set. The second set of data involves the discourse marker "haide" which is argued to externalize features associated with the force of the sentence and its anchoring to the discourse participants. In the case of modal particles, the languages under consideration retain their own lexica, while in the case of the discourse marker, they share the same lexical item (lexical borrowing). Analysis of these phenomena supports an articulated left periphery which also accounts for the similar distribution of the discourse marker "haide". At the same time, the different externalizations leave room for further microparametric variation.
\end{abstract}

Keywords: externalization; discourse; future; I-language; lexical borrowing; microvariation; modality; subjunctive

\section{Introduction}

The languages of the Balkans (Greek, Albanian, Balkan Slavic, Balkan Romance, Balkan Romani, and their varieties) show typological similarities, although they are not immediately related. Lindstedt (2000) describes twelve such properties across the nominal and verbal domains considered as "grammatical innovations" that give rise to "Balkanisms". Tomić-Mišeska (2004a, p. 4) reduces these innovations to six, as follows: analyticity in the nominal domain (e.g., genitive as a PP), definiteness through an enclitic determiner $(\mathrm{N}+\mathrm{D})$, pronominal clitic doubling, periphrastic expressions of the future and the perfect (with "have"), and substitution of former infinitival forms with "subjunctive clauses". She further points out that "Balkanisms" arise in the "area around the southern parts of the lakes of Ohrid and Prespa, where Greek, Albanian, Macedonian and Aromanian intersect. The structures of the local dialects of the languages spoken in this area are actually very perspicuously similar to each other" (p. 2). In other words, Balkanisms are not independent of situations of language contact in multilingual areas. The similarities observed may not hold for all languages of the Balkans but to the extent that this is the case, they show correspondences between various grammatical systems at the level of E-languages.

The focus of the present paper is on the left periphery and particularly on two sets of data that have been studied in the literature. The first set involves the analytic expressions of the "future" and the "subjunctive", as mentioned by Tomić-Mišeska (2004a), while the second involves the discourse marker "haide". Let us start with the first one. Regarding the expression of the "future", this takes a morpheme, (usually) originating from a volitional verb like "want", which is followed by a finite form of the verb. The "subjunctive clause" also involves a morpheme, usually originating from a conjunction, followed by a finite form of the verb. The two patterns are roughly illustrated in (1) and (2), respectively: 
1. $\{$ Greek tha, Albanian do, Balkan Slavic šte, ... \} + finite verb

2. $\{$ Greek $n a$, Albanian të, Balkan Slavic da, Balkan Romance să, .. \} + finite verb

As one can see in (1) and (2), the languages in question make use of different lexical items, although on the surface at least, the pattern is the same, i.e., [Particle-V]. The "subjunctive clause" can occur as a matrix sentence, in which case it has the distribution of a morphological subjunctive, or as an embedded clause, in which case it basically has the distribution of the infinitives or that of the (Romance) subjunctive in some limited cases. Strictly speaking then, the Balkan "subjunctive clause" is an altogether different formation from its Romance counterparts, and despite its distribution in otherwise infinitival contexts, it is not an infinitive either. For present purposes, we will keep the terms "future" and "subjunctive" for descriptive purposes only, in order to describe the two sets of periphrastic constructions. Similarly, we will use the term "particle" as a descriptive term that unifies the two sets of morphemes under consideration, bearing in mind that it is used functionally and not formally at this stage.

Another case arises once we consider the discourse marker "haide" with the following realizations in Bulgarian (Tchizmarova 2005), Romanian (Hill 2008; Haegeman and Hill 2013), Greek (Roussou 2017), and Albanian:

\section{Bulgarian xajde, Romanian haide, Greek ande, Albanian hajde}

A quick look suggests that the elements in (3) have a common origin, which is attributed to the Turkish haydi "come/go" due to lexical borrowing (see Tchizmarova 2005 for references). Interestingly, the adapted items show similarities both in terms of distribution and in terms of interpretation, pointing towards morphosyntactic properties which go beyond lexical borrowing. While, in the case of modal particles, the languages in question retain their lexica, in the case of the discourse marker in (3), they use a borrowed lexical item. On the assumption that discourse markers can interact with the left periphery of the clause, we include (3) in our discussion as well.

The present paper considers these two basic sets of data, namely the modal particles which participate in grammatical relations and the discourse marker "haide" which has expressive content. The discussion is based on empirical data that have been studied in the literature, and as such, its aim is not to expand the empirical base but to explore how these similarities can guide us to a better understanding of the articulation of the left periphery and how the various externalizations can provide us with an understanding of the Ilanguages. On this basis, the paper has two objectives. The first one relates to the properties of the modal particles and aims to show that the languages under consideration converge on the articulation of the left periphery, although this convergence is, to a very large extent, triggered by internal changes affecting individual grammars. The second objective relates to the properties of the marker "haide" in the grammar of the languages under consideration. It is shown that the common properties are consistent with the articulation of the Balkan left periphery. As we will see, although there are clear correspondences, there is lots of microvariation as well.

The paper is organized as follows. Section 2 discusses the articulation of the left periphery and considers the distribution of the two sets of modal particles. Section 3 discusses the distribution of the discourse marker "haide" based on data from Romanian, Greek, Bulgarian and Albanian. In these two sections, the aim is to show that the lexical items under consideration are externalizations of different features associated with the left periphery. More precisely, it is argued that the future markers are construed as V-related elements externalizing a scope position of the verb. On the other hand, subjunctive markers take their features from the nominal domain and function as linkers (following Manzini and Savoia 2018). The discourse marker "haide" is a different case as it externalizes features associated with the force of the sentence and its anchoring to the discourse participants (speaker, hearer/addressee). Section 4 offers some concluding remarks in relation to the I-language perspective. At this point, a clarification is necessary: the aim of the discussion is not to provide an account of language contact but, given this recorded contact, to consider 
how the various externalizations which reflect "surface similarities" can guide us to obtain a better picture of I-language properties.

\section{The Modal Particles and the Left Periphery}

\subsection{The Subjunctive and the Future}

As pointed out in the preceding section, a common characteristic of the languages of the Balkan peninsula is the use of a "modal particle" for the syntactic expression of the future or the subjunctive/infinitive. As will be shown immediately below, these elements participate in grammatical relations which involve the expression of modality (and partly of tense) or affect the proposition they embed in a way to be made more precise. Given the grammatical features they realize, they are obligatory in the relevant syntactic contexts.

Let us start with the following basic data from Rivero and Ralli (2001, p. 7). In the examples below, Bulgarian represents the Balkan Slavic group and Romanian the Balkan Romance:

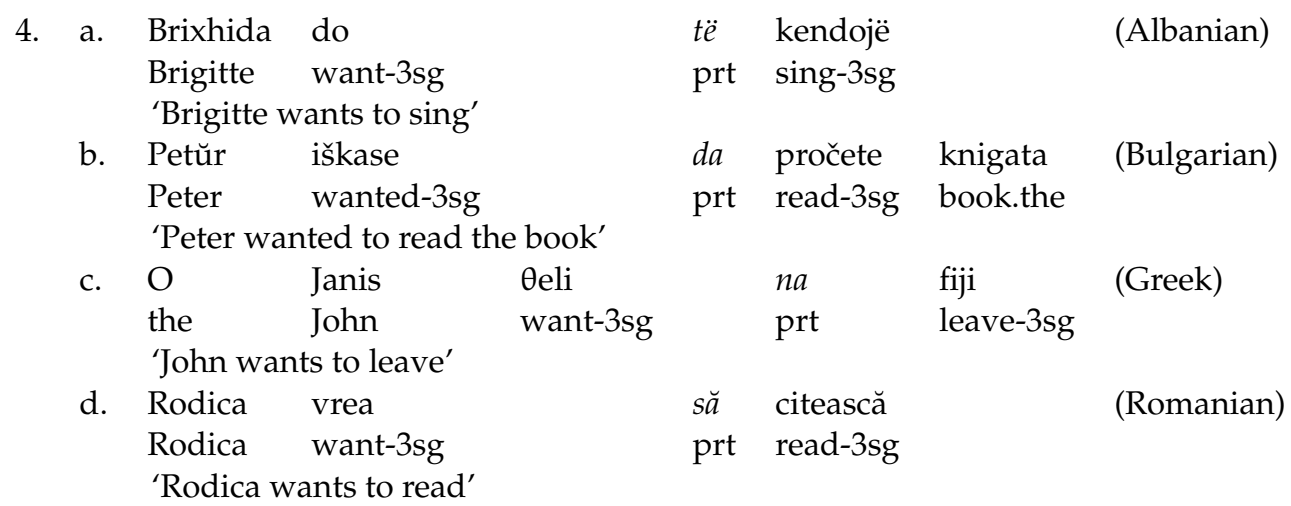

In the above examples, the "subjunctive clause" occurs in a complement position (selected by "want") and is introduced by the corresponding italicized particle.

The data in (4) are subject to variation. For example, Albanian and Romanian have retained some forms of the subjunctive morphology on the verb (see Turano 2017; Manzini and Savoia 2018; Dobrovie-Sorin 1994; Hill 2013a). Furthermore, the të and să particles can be embedded under a specialized complementizer, $q \ddot{e}$ and $c a$, respectively. These complementizers differ from the indicative ones (Albanian se, Romanian că); the Albanian example below is from Turano (2017, p. 63), and the Romanian from Dobrovie-Sorin (2001, p. 55):

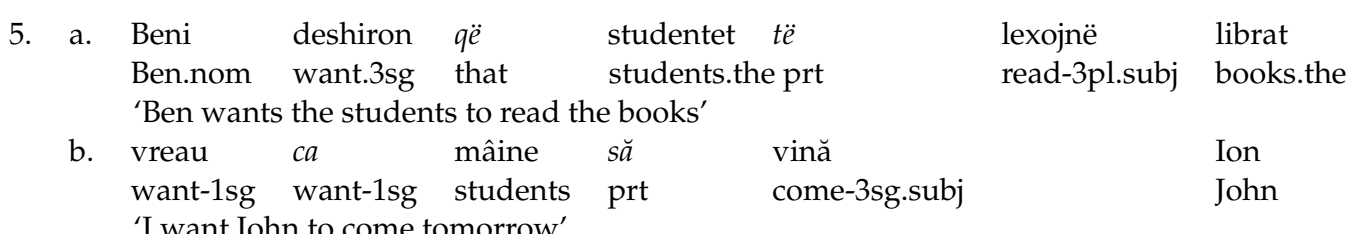

Another dimension of variation concerns negation. Albanian and Greek, for example, distinguish between a modal and a non-modal negator. Thus, the negator $m i$ in Greek is selected by $n a$ (in both matrix and embedded clauses), and the negator mos in Albanian is selected by të (Joseph 2001); the non-modalized negators are ðen in Greek and s' or nuk in Albanian (for the latter, see Turano 2000). The finite verb follows the particle and the negator in case the latter is present:
6. a. na mi-V
b. të mos-V

Note that the [Subjunctive Particle-Neg] order in (6) does not necessitate the availability of a modal negator. For example, Romanian and Bulgarian, which do not distinguish between a modal and non-modal negator, also have the order [Subjunctive Particle-Neg], i.e., să $n u(\mathrm{R})$ and $d a n e(\mathrm{~B})$. In short, despite variation regarding the lexicalization of negation, 
the relevant order between the subjunctive particle and negation is the same: the negator follows the subjunctive particle.

A third dimension within the Balkan Slavic group concerns the morpheme $d a$, which in Serbian (as in Croatian) is also the form of the declarative complementizer. Whether it is the same lexical item, or two homophonous lexical ones, is open to discussion. For example, Todorović (2012) argues for two distinct (i.e., homophonous) lexical items (da1 vs. da2). Note that Bulgarian and Macedonian do not show this pattern and have one instance of $d a$ restricted to subjunctive clauses. The indicative (declarative) complementizer takes a different form, namely če or deto (the latter for factive complements and relative clauses) in Bulgarian (Krapova 2010) and deka in Macedonian.

Considering the common characteristics of these particles, Rivero (1994) argues in favor of a uniform clause structure, as in (7) below (her (11)):

\section{7. [CP [NegP [ModP [TP/AgrP [(AuxP) [VP ...}

In (7), the subjunctive particles realize the Modal (Mod) head. The specialized complementizers realize the $C$ head-in languages like Greek or Bulgarian which do not have this distinction, $\mathrm{C}$ is realized as null in the presence of the subjunctive particle. The hierarchy in (7) should give us the order Neg-Subjunctive Particle, contrary to fact. As we saw in (6) above, the attested order is the reverse. Rivero argues that this is due to incorporation of the subjunctive particle (the Mod head) to the Neg head, thus yielding the correct order:

\section{8. $[\mathrm{Mod}+\mathrm{Neg}[\mathrm{MoP} \operatorname{Mod}[\mathrm{TP} / \mathrm{AgrP} \ldots=$ na mi/të mos/să nu/da ne}

Leaving aside the technical details of her analysis and the motivation for incorporation, Rivero's account is perhaps the first attempt to provide a uniform clause structure for the Balkan languages, building on what Sims and Joseph (2019) identify as "surface similarities". In other words, despite variation, at an abstract level, the empirical data map onto the same invariant structure. This has certain advantages but at the same time, it leaves little room for microvariation.

Before we discuss the various options regarding the position of the "subjunctive" particles and their interaction with complementizers and negation, let us look at the other modal particle for the "future". Rivero (op. cit.) argues that the structure in (7) also accounts for the distribution of the future particles. More precisely, just like the subjunctive ones, they occupy the Mod head; they are accordingly predicted to follow negation and precede the finite verb (or the clitic-V cluster). The schema in (7) also accounts for the fact that the subjunctive and the future particles cannot co-occur, since they compete for the same position. In more recent terms, this could mean that they are both externalizations of Mod. As we will see below, the two particles have distinct properties and should be kept apart; in other words, we next show that they realize different features and, as such, realize distinct positions in the clause structure.

Let us now turn to the analytic future, which is another "Balkanism". The future is formed with a particle followed by the finite verb; the data below are adapted from Joseph (2001, p. 3):

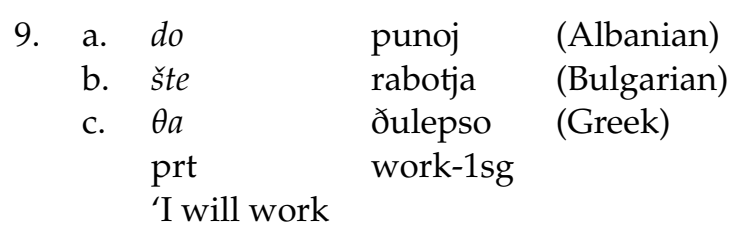

In Albanian, the particle is do, in Bulgarian šte (Serbian ću), in Greek tha, etc. Historically, these particles derive from a volitional verb, for example dua in Albanian, $\theta$ elo in Greek. To some extent, the data in (9) are reminiscent of the English future formation, where a former volitional verb, namely will, becomes an auxiliary modal that embeds the verb in its bare form (essentially the stem). Unlike English though, the formations in (9) embed a fully inflected (finite) verb. Assuming that the main verb is realized in $T / \mathrm{I}$, the particle is 
expected to realize a higher position. Again, this is supported by the position of pronominal clitics which (can) follow the particle (for variation, see below).

It is also worth pointing out that the combination of the future particle with the verb does not necessarily receive a future tense interpretation but can give rise to other modalities depending on the inflectional properties of the main verb. For example, in Greek (9c), the verb is marked for perfective aspect; the future reading may also arise with the imperfective specification, $\theta a$ dulevo; the latter may also be compatible with an epistemic reading. A +past, +/-perfective specification (ðulepsa or $\partial u l e v a)$, on the other hand, excludes a future reading, allowing for modal readings only (e.g., counterfactual, epistemic, etc.) (see Tsangalidis 1999). The Bulgarian example in (9b) has imperfective aspect, and also corresponds to a future reading (see, for example, Tomić-Mišeska 2004b on the Balkan Slavic). The aspectual distinction is not relevant to Albanian and Romanian.

An alternative formation attested in many Balkan varieties involves the future particle followed by a subjunctive clause, instead of the finite verb, as in the examples below from Sims and Joseph (2019, p. 100):

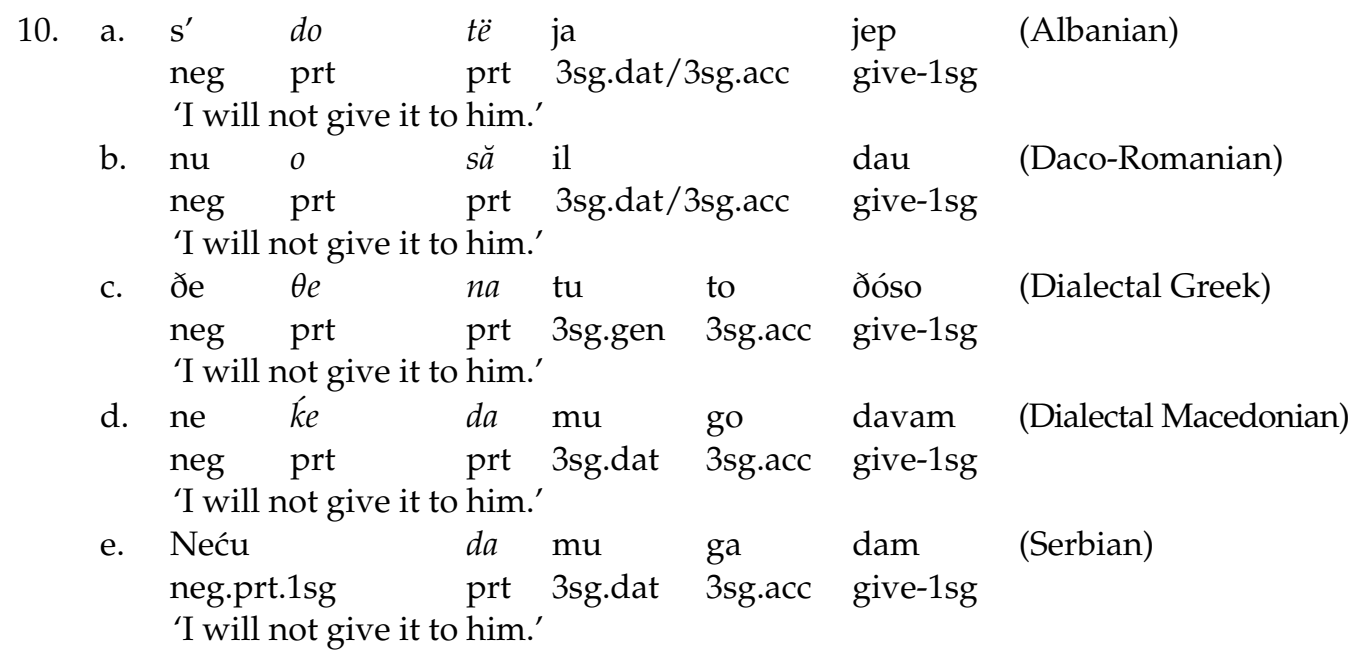

In Albanian (10a), do, which is the 3rd person singular of the verb dua "want" (Camaj 1984, $\S 182-86)$, takes a subjunctive të-complement. ${ }^{1}$ In Daco-Romanian (standard Romanian) (10b), the form $o$ (originally from the verb vrea) takes a să-complement; in Greek varieties, $\theta e$ (a reduced, uninflected form of the verb $\theta e l o$ "want") takes a na-complement (Markopoulos 2009). Finally, in Macedonian varieties (10d), ke takes a da-complement, and the same holds for Serbian (negative) nес́ in (10e). This variation reflects different diachronic stages in the development of the future which is also related to the independent replacement of the infinitive by a subjunctive clause (for example, see Markopoulos 2009 for Greek, Nicolescu 2011 for Romanian).

Related to the above is the discussion in Tomić-Mišeska (2004b) which offers a fairly thorough examination of the Balkan Slavic future. Tomić distinguishes three basic patterns, which correspond to three diachronic stages in the development of the future. The first stage involves the future particle, which derives from the verb "want", which takes an infinitive; the second stage involves the future particle followed by a $d a$-complement, while

1 According to Camaj (1984), të can be missing in Southern Tosk varieties (see (9a)). 
the third stage involves the future particle followed by a finite form of the verb. ${ }^{2}$ These patterns are illustrated in the following examples from Serbian/Croatian varieties. ${ }^{3}$

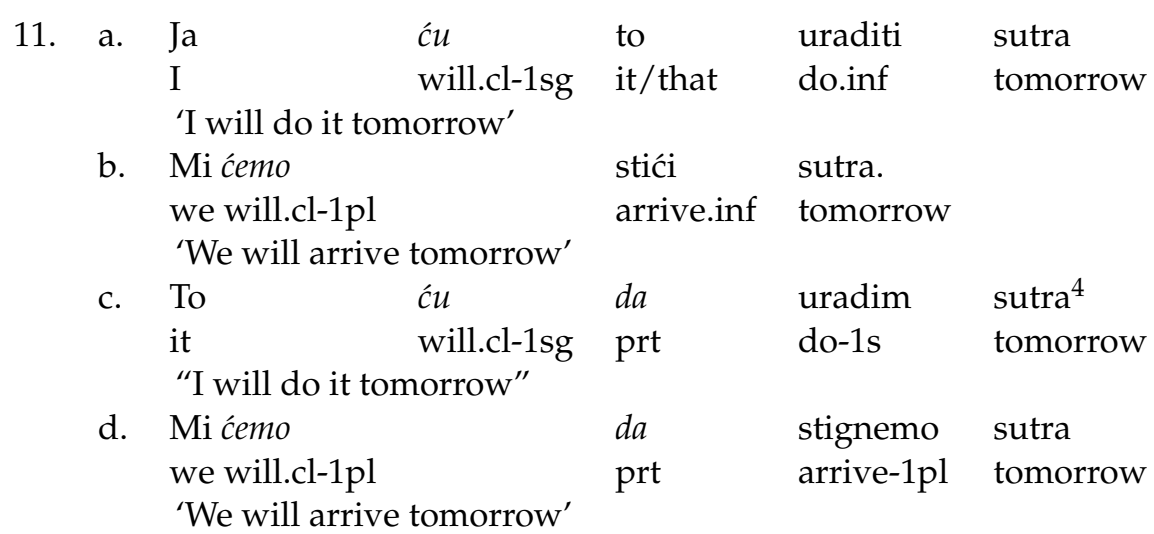

According to Tomić, the infinitive is attested in Croatian, but as one moves southeast in Serbian varieties, this becomes less common giving place to formations with the subjunctive clause or the finite verb only, as in (11c). The morpheme $c u$ is the clitic version of the lexical verb hoć "want". Interestingly, when its complement is an infinitive, the future morpheme inflects for person, as the contrast between (11a) and (11b) shows. On the other hand, when the complement is a da-clause, the clitic auxiliary and the embedded verb agree in person and number. Tomić offers a very detailed picture including examples with southeastern varieties, Macedonian $k e$, and Bulgarian šte, which behave more like Greek $\theta a$.

The brief presentation above is meant to show that even if we restrict our attention to two common features in the Balkan languages, that is the "subjunctive" and the "future" particles, we can find lots of variation despite similarities. The subjunctive particles-usually originating from conjunctions-take a finite form of the verb. They precede clitics and negation and may select a specialized negator. A further variation includes the option of having a designated complementizer (Albanian and Romanian) that introduces the subjunctive complement. The "future" particles show more variation. The ones mentioned above derive from a volitional verb like "want". The attested variation concerns their own form, which could retain its verbal characteristics and inflect or be reduced to a base form. Another parametric dimension involves their complement, varying from an infinitive, to a finite verb, to a subjunctive complement.

\subsection{Modal Particles and the Left Periphery}

The picture that emerges so far, although limited to a small set of data, suffices to show two main things. First, there are clear correspondences among the Balkan languages based on the modal particles, and second, there is microvariation regarding their properties. The similarities and differences also reflect stages in their historical development. For example, the future particles have derived from a volitional verb whose complement was an infinitive, which was subsequently replaced by a subjunctive, that is another analytic formation, or the infinitive was reanalyzed as a finite verbal form. On the other hand, subjunctive particles have developed out of conjunctions which would typically embed a verb in the subjunctive mood (for an overview, see Roberts and Roussou 2003). The stages in diachronic development are not always well-documented in all Balkan languages and

2 Note that the infinitive survives in some Balkan languages, but is limited to certain syntactic contexts (see Joseph 1983; for Romanian, see Dobrovie-Sorin 1994; for Albanian and Romanian varieties, see Manzini and Savoia 2018).

3 Tomić-Mišeska (2004b) uses the term Serbo-Croatian to include various varieties in Croatian and Serbian. A reviewer points out that Serbian is not part of the Balkan Sprachbund. In fact, which languages are members of the Sprachbund or which ones are at the core vs. the periphery is a question that has received different answers. This discussion is summarized in the introductory chapter of Tomić-Mišeska (2006). Serbian is not considered in the present discussion; however, the data in (11) are interesting because they show a variation as one moves southeast towards "core" Balkan languages like Macedonian.

4 Note that in (11c) we have an instance of clitic climbing, hence its presence above the auxiliary clitic. These grammars show further complexity due to the fact that auxiliary verbs are also clitics. The positioning of clitics is also subject to Wackernagel's law. 
varieties. Nevertheless, they are indicative of how the currently attested correspondences have emerged. Although the diachronic development sheds some light on their current status, it cannot be the explanation for their synchronic status and what this reveals with respect to the syntactic properties they externalize.

Given the above clarification, we can now turn to the main question, which is precisely this: What can the above patterns tell us about morphosyntax? How do we proceed from the specific lexical items (the modal particles) to their syntactic properties? To put it differently, how do we move from the various externalizations to the I-languages? Recall that in Rivero's (1994) analysis, there is a uniform Balkan clause structure, which does not distinguish between the two sets of particles and does not seem to allow for much microvariation. Let us see what sort of generalizations we derive from the data we have looked at so far. Descriptively, we have two general schemata for the future and subjunctive particles, accordingly, further illustrated with the lexical sequences in (14) for the future and in (15) for the subjunctive. With respect to the future formations, we restrict our attention to those where the future particle is followed by a finite verb, as in (14a), or a subjunctive clause as in (14b). The option with the infinitive following the future particle can be accommodated (partly at least) under (12a):

12. Future particles

a. NEG-FUTURE PARTICLE-CLITICS-VERB

b. NEG-FUTURE PARTICLE-SUBJUNCTIVE CLAUSE

13. Subjunctive particles

SUBJUNCTIVE PARTICLE-NEG-CLITICS-VERB

14. a. Greek:

Albanian:

Bulgarian:

Macedonian:

b. Greek (varieties):

Albanian:

(Daco-)Romanian:

Macedonian (varieties):

15. Greek:

Albanian:

Bulgarian:

Macedonian:

Romanian:

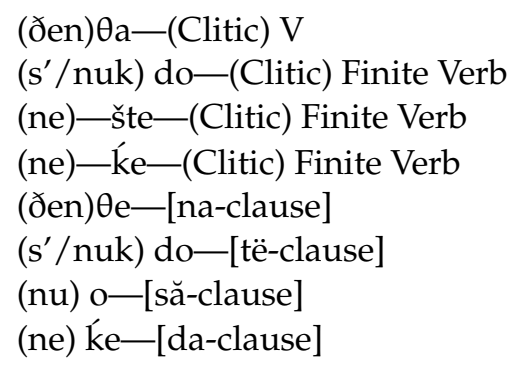

Recall also that in Greek and Albanian, the subjunctive particle selects its own negator (mi/mos). Therefore, at a descriptive level and given the observed variation, we can assign different positions to the two sets of particles, with the subjunctive occupying a higher position and the future a lower one, still both above the inflectional domain, given that pronominal clitics precede the verb (proclisis) but follow the particles in either case. The schemata in (12) and (13) do not support Rivero's structure which puts them in the same Mod position, unless some additional mechanism, such as movement, is invoked. It is worth mentioning at this point that other accounts treat them differently. For example, Philippaki-Warburton (1998) assigns different properties to $n a$ and $\theta a$ (mood and future tense, respectively), while Tomić-Mišeska (2004b) takes future particles to be Modal and subjunctive particles to be Mood heads.

A second major difference is that there are varieties where the future particles seem to retain some verbal characteristics. For example, Albanian do is the 3rd person singular of the verb dua "want". As a lexical verb, dua inflects for person in both numbers (dua, do, $d u a m$, etc.); as a future particle, it does not. Greek $\theta a$ or $\theta e$ is the reduced stem of the verb $\theta e l o$ "want" which, as a lexical verb, fully inflects $(\theta e l o, \theta e l i s / \theta e s, \theta e l i$, etc.). In some varieties, the future particle retains the full stem with the invariant affix $-a$, i.e., $\theta$ ela, followed by the 
finite verb. Bulgarian šte is also uninflected as a future marker, but fully inflects as a main verb (šta, šteš, šte, etc.) (for a descriptive presentation regarding Bulgarian and Macedonian, see Lindstedt 2010). To the extent that the original volitional verb survives in the languages under consideration, we observe that the future particle is either a form that coincides with the 3rd person singular, or an uninflected form (stem, or a reduced form of the stem). Recall also that in the Serbian varieties discussed by Tomić-Mišeska (2004b) (examples in (11) above), the expression of the future may involve an inflected form of the verb.

The above discussion points towards a different categorization of the two particles. Their distributional properties, their position with respect to negation, and their (non-) overlap with verbal forms support an approach which assigns them different features associated with distinct heads in the clause structure. Recall also that in Albanian and Romanian, subjunctive clauses can be embedded under a specialized complementizer, that is $q \ddot{e}$ and $c a$, respectively. On the other hand, future particles are embedded under the indicative (declarative) complementizer, se and $c \breve{a}$, respectively. As pointed out by a reviewer, the specialized complementizers are incompatible with the future particles even when these embed a subjunctive clause:

16. *Subjunctive C-Future particle-Subjunctive clause
a. ${ }^{*} q \ddot{e}$ do të - Verb
(Albanian)
b. $\quad{ }^{*} c a$ o să - Verb
(Romanian)

The ungrammaticality in (16) shows that there are selectional restrictions between complementizers and modal particles and these restrictions are subject to locality.

Let us now turn to the syntactic positions these particles realize. Recall that Rivero (1994) argues for a Modal (Mod) position which is realized by the subjunctive or the future particles. We have shown that this is not satisfactory for a number of reasons. On the other hand, if we take pronominal clitics to be indicators of the inflectional domain, the realization of modal particles above the pronominal clitic (or clitic cluster) can be taken as a piece of evidence for the merger of the future/subjunctive particle in the left periphery (or at the border between the left periphery and the inflectional domain). The data discussed so far can be more easily accommodated once we bear in mind the articulated left periphery. Rizzi (1997) argues that C splits into two separate heads: Force and Fin. Between these two heads, we can find topics and/or foci (see also Rizzi and Bocci 2017), as in (17):

\section{7. [Force $[($ Topic) /(Focus) [Fin [I}

In Rizzi's account, these two positions may be realized by all sorts of different elements, such as complementizers (Italian che), prepositional complementizers (Italian di) or verbs (as in V2-constructions). As such, they label positions whose externalization is not categorially restricted. The structure in (17) has been employed for the subjunctive particles in Balkan Slavic and Balkan Romance by Hill and Mišeska-Tomić (2009) (a more recent account for Romanian is provided by Hill 2013a). Adding yet another category, that of modal particles, on the one hand enriches the range of elements that may externalize either of these two heads, but on the other hand, it maximizes the problem of categorial restriction.

Let us follow a different approach and assume, adopting and adapting ideas in Manzini and Savoia (2011), that Force and Fin are scope positions of the verb. As such, they can be targeted by the main verb or an auxiliary. To be more precise, Force can be understood as a position for the intensional properties of the clause (a sentential Operator position, in other words). As we will see in Section 4, this position can be realized by an imperative verb. For present purposes, I will use the label Force. Consider next Fin. Its characterization is rather vague, as apart from the $+/$-finite distinction, it may also host mood (irrealis) features (Rizzi 1997). The Balkan languages have finite inflection on the verb which, at least in declarative clauses, is in I/T (Rivero 1994). In this case, it would be more relevant to treat Fin as a modal position, which modifies the verb and ascribes to it and the clause certain modal readings (at least those associated with the analytic future). Let us then call this position Modal (M) and keep it distinct from mood, which we assume is an inflectional category. The structure in (17) is modified as in $\left(17^{\prime}\right)$ : 


\section{7'. [Force [(Topic)/(Focus) [M [I}

One additional note is necessary: under this set of assumptions, typical complementizers and prepositional complementizers are not externalizations of Force or M/Fin. We will assume that complementizers merge as arguments of the selecting predicate embedding the clause they select; as such, they are nominalizers. Prepositional complementizers, on the other hand, are treated as prepositions, introducing clauses as oblique arguments (for a recent view, see Manzini and Roussou 2020). We will not discuss them further, as their properties are not part of the present discussion.

The question that arises now is whether the modal particles are realizations of Force, $\mathrm{M}$, both or neither. The immediately preceding discussion has already hinted towards their $\mathrm{M}$ status. Since future particles do not participate in the force specification of the clause (e.g., they are found in declaratives or interrogatives), they do not qualify as externalizations of the Force head. This leaves us with the lower M position, which is (also) a scope position of the verb. Given that the verb is in a lower position, namely I/T, the future particle that merges in $\mathrm{M}$ is part of the V-chain, as in (18):

\section{8. [(Neg) [M $\theta a /$ do/šte/ke [(Clitic) [I/T V ... . .]]]]}

The future particle, in other words, is an auxiliary (clitic) which externalizes the M position of the V-chain. In other words, two positions of the chain are spelled out by different morphemes. The structure in (18) covers the pattern in (14a), where the future particle is followed by a finite verb. Being in a chain, the two elements are interpreted as one, with each lexical item contributing different features for the purposes of interpretation. Thus, while $\mathrm{V}$ provides the argument structure and features for tense (and/or aspect) and agreement (the EPP slot) via its inflectional affix, the future particle (as an auxiliary V), modifies it along the futurity/modality dimension (see Roussou 2015). The future particles are preceded by negation and are in the scope of negation. Note that Rivero (2005) also argues that the future particle (along with other clitic auxiliaries) in Bulgarian is part of the extended projection of the verb; the restriction to a single EPP position unifies them as "one" verb. Despite sharing this idea, the present account differs from that of Rivero (2005) in that it does not extend it to the subjunctive particle, among other things. The other pattern with the future particles is the one in (14b), i.e., Future particle + Subjunctive clause. We will discuss this once we have considered the subjunctive particles.

Unlike future particles, subjunctive particles do not have any verbal correlates. Historically, they draw on conjunctions (e.g., a locative subordinator in Greek, a conditional subordinator in Romanian, a connector in Albanian). Historical evidence may be inconclusive or not available for all of them (for example, does Balkan Slavic da relate to the affirmative marker $d a$ "yes"?). Recall from our discussion in Section 1 that the Balkan subjunctives have a mixed distribution: in main clauses, they resemble morphological subjunctives while in embedded clauses, they largely resemble infinitives and may not necessarily be associated with modality (see Roussou 2009). This mixed behavior is reflected in the debate about their status as mood markers or complementizers. A more promising account would be to assume that they are simply different entities, i.e., neither mood markers (despite their label) nor complementizers. Restricting the category mood to an inflectional category, of the limited type still attested in Albanian and Romanian, further provides an answer to their exclusion from this category. On the contrary, the subjunctive particles either introduce a verb with subjunctive morphology (where available) or an indicative form of the verb. In the latter case, we would expect a feature clash between a subjunctive feature (the particle) and an indicative form (the inflection on the verb), contrary to fact. On the other hand, treating subjunctive particles as complementizers is also problematic. Recall that at least Albanian and Romanian allow subjunctive clauses to be introduced by a specialized complementizer. The term "subjunctive particle" then seems to be a label that reflects diachronic stages in the development of these formations but turns out to be a misnomer with respect to the actual lexical items involved. 
Let us take a closer look at some of these particles at least. Considering the Albanian të particle, Manzini and Savoia (2018, Chp. 8) argue that it is the same element found in the nominal domain as a linking article, as in (19) (we leave it unglossed at this point):

19. disa

some

'some nice boys' djem

boys të

të bukur

nice

The $t \ddot{e}$ morpheme in this case establishes a predicative relation between the noun and the adjective; in other words, it is a linker whose agreement properties put it in the nominal set of features. In categorial terms, Manzini and Savoia (op. cit.) classify it as D and further argue that this specification extends to the subjunctive të; Sonnenhauser and Widmer (2019) also unify the article and the subjunctive $t \ddot{e}$, further offering historical evidence for the development of the subjunctive use.

Restricting our attention to the subjunctive function, we observe that at least in complement clauses, të establishes a relation between the selecting predicate and the embedded clause. More precisely, it turns the clause to a predicate (a $\lambda$-abstractor) by introducing a variable (it opens the proposition in other words). This variable corresponds to the EPP slot of the clause. Note that the EPP property is saturated by finite inflection in Albanian (it is a pro-drop language). By providing a variable, të allows for a bound reading of the embedded subject, as long as the selecting verb is a control predicate. If not, the option of the EPP retaining its pronominal reading remains. The latter also holds for tëmatrix clauses where furthermore, the predicative property blocks the declarative reading and forces a modal reading. Under this approach, the modal reading is not inherent to the $t \ddot{e}$-clause but arises due to its presence in the left periphery where modal and discourse properties are represented. Adapting their analysis, we assume that $t \ddot{e}$ realizes a D position in the scope of Force in matrix clauses:

\section{0. [(Force) $[\mathrm{D}(\mathrm{Lkr}) t \ddot{e}[\mathrm{Neg}(\mathrm{mos})[\mathrm{CL}[\mathrm{T} / \mathrm{I} \mathrm{V} \ldots .]]]$.}

According to (20), what makes të different from the future particle do is not only the position where it merges in the left periphery but also the features it realizes. Recall that do as a future particle is a V-element that modifies the verb. On the other hand, të relates to the EPP slot via the verbal inflection, and more precisely, the agreement affix on V. Both particles are clitics, but of different kinds: the subjunctive is a "nominal", while the future particle is a "verbal" one.

Could this approach extend to the subjunctive markers in the other Balkan languages under consideration? The answer would (probably) be yes. At least with respect to Greek, it has been argued that $n a$ is also a morpheme with a nominal feature specification that is also found as a deictic element in presentational contexts (Christidis 1985, adopted and adapted by Roussou 2009). For present purposes, we take D as a cover term that encompasses features of the nominal set (e.g., agreement). It is possible that the subjunctive particles in the languages under consideration show finer distinctions, that is externalizing different features from the nominal set. With respect to Albanian, the historical and synchronic morphosyntactic evidence seems to support the view that the article and the subjunctive article are the same entity, with the function of the linker. This argument can also extend to Greek, given that $n a$ is also found as a deictic (demonstrative) element in presentational contexts. The obvious question is to what extent this argument is valid for the other Balkan languages. Do we have sufficient morphosyntactic evidence regarding Balkan Slavic da and Balkan Romance să for example? Syntactically, the crucial evidence rests on the role the subjunctive particles play in complement clauses and in particular with respect to control. More precisely, control in the Balkan languages requires the presence of a "subjunctive" particle. This is a one-way implication, since not all subjunctive complements are control contexts - the latter also depends on the semantic properties of the selecting predicate (see Landau 2013 for an overview). Control is a relation that affects the subject, i.e., the EPP slot, of the embedded clause, and as such, relates to an argument of the predicate and not the 
predicate itself. It is on this basis then that we take subjunctive particles to have features of the nominal set, even when the morphological (and historical) evidence is not sufficient.

Based on the above, we assume then that a generalized account of subjunctive particles as variants of the same general category is possible. This is further supported by the fact that they behave alike when they introduce matrix clauses as well, i.e., they trigger a modal reading and cannot be construed as declaratives. In this respect, the schema in (20) could be generalized to Greek, Bulgarian, Macedonian, and Romanian (the languages we have considered so far), as in (21) — there is room for microvariation regarding the position of negation, Topic, Focus, etc.:

\section{1. [(Force) $[\mathrm{D}(\mathrm{Lkr}) n a / t \ddot{e} / d a / s a ̆[(\mathrm{Neg})[($ Clitic) $[\mathrm{T} / \mathrm{I} \mathrm{V} \ldots$ ] ] ]]]}

At this point, we can assume that the Force layer is absent in complement clauses (unless its presence is necessitated by the selecting predicate, an issue which we leave open); note that the latter would bring Balkan embedded subjunctives closer to the Italian subjunctives discussed by Giorgi (2010). Although the discussion is not conclusive, it can form the basis for further comparative and theoretical research.

To summarize the discussion so far, we have argued that the future and the subjunctive particles are distinct and relate to different (operator) features associated with the verb ("future") or its EPP inflection. The present approach does not exclude the possibility of finer distinctions across grammars along the verbal vs. nominal classifications.

We are now in a position to go back to the future formations in (14b), where the future particle takes a subjunctive complement. The question that arises is whether we have a mono-clausal structure, as in (18), or a bi-clausal one given the presence of the subjunctive particle. The question as to whether these formations are mono-clausal or bi-clausal has been a topic of debate in the literature. For example, with respect to Bulgarian, Rivero (2005) argues in favor of a bi-clausal structure, while Hill and Mišeska-Tomić (2009) argue in favor of a mono-clausal analysis for Balkan Slavic and Balkan Romance. Given, as we saw above, that the subjunctive particle occupies a position in the left periphery of an articulated structure, which is arguably above $\mathrm{M}$, as the position of negation indicates, we can assume that the future particle embeds a clausal complement. If this is correct, then we have a bi-clausal structure, as in (22). For expository purposes, we keep the labels "future" and "subjunctive" particle:

\section{2. [M Future particle $[\mathrm{I} / \mathrm{T} \ldots$. [D(Lkr) Subjunctive particle [ . . ] ]]]}

In the configuration in (22), the main verb is introduced as part of a clause headed by the subjunctive particle, which according to what we have said so far, turns the clause it embeds into a predicative structure. The future particle in this case behaves like its lexical counterpart which also takes a subjunctive complement. The crucial difference lies in the fact that the reduced (clitic) form of the verb does not have a volitional interpretation, and also lacks an external argument. Its EPP property is satisfied by the features of the embedded clause, as in raising constructions. If this is on the right line, (22) is structurally bi-clausal due to the mediation of the subjunctive particle, but mono-clausal for interpretive reasons. Given that the subjunctive particle does not merge in the left periphery of the clause headed by the future particle, we correctly predict that it does not define the force properties of the clause. Indeed, these (modal) sentences remain declaratives (or interrogatives accordingly). Note further that, as shown in (10), negation occurs in the matrix clause and takes scope over the whole structure (cf. s' do të- $V$ in Albanian; ðe $\theta e$ 
$n a-V$ in Greek, etc.). ${ }^{5}$ Further empirical evidence is required but at this point, the idea of having a bi-clausal structure can be empirically supported, primarily based on the presence of the subjunctive particle.

To summarize the discussion in this section, we have considered the future and subjunctive particles. We have argued that the two particles are externalizations of different features and despite similarities, they modify different properties associated with the verb they embed. Future particles are part of the V-chain and correspond (at least) to a scope (M) position of the verb. Subjunctive particles, on the other hand, relate to the nominal features and behave like ( $\lambda$-)operators which either link two predicates (complementation) or are in the scope of an intensional (Force) operator (matrix clauses). It is worth pointing out that the above approach recognizes two basic sets of features: those that relate to the verb and those that relate to the noun. For Chomsky (2020), the predicative (categorizer v) and the substantive (categorizer $\mathrm{n}$ ) are "fundamental notions", which further qualify as phase markers. As argued in this section, the distinction between future and subjunctive particles builds on this basic distinction. In the next section, we turn to the second set of data and consider the discourse marker "haide".

\section{Discourse Markers: The Case of "Haide"}

\subsection{The Empirical Data}

We now turn to the pattern introduced in (3) in Section 1. The syntactic properties of these elements have been discussed in the literature with respect to Romanian haide (Hill 2008, 2013b; Haegeman and Hill 2013) and Greek a(i)nde (Roussou 2017). Tchizmarova (2005) discusses Bulgarian xajde $\mathrm{t}$ focusing on its pragmatics and not on its syntactic properties. As mentioned in Section 1, these variants are assumed to derive from the Turkish haydi "come/go" and roughly translate as "C'mon" in English (see Tchizmarova 2005 for references, and the discussion in Nicholas 2010). Romanian has a short form as well, namely hai, and the same holds for Greek ai. Unlike the modal particles that we discussed in the previous section, here we have a case of the same lexical item-or the same lexical base-and, as we will see, with a very similar syntactic distribution (for an overview of the literature on discourse particles or markers, see Maschler and Schiffrin 2015).

Let us start with the following examples from Romanian (Hill 2008, 2013b; Haegeman and Hill 2013). The hai/haide forms are left unglossed:

5 An anonymous reviewer points out that, at least with respect to Romanian, the idea of a bi-clausal structure may be problematic for the following reasons. First, coordination forces the repetition of the future particle, as in (i). Second, ellipis cannot strand the future particle only, but requires deletion of the whole $o s \breve{a}-\mathrm{V}$ constituent, as in (ii). Finally, the future particle cannot coordinate with another modal, as in (iii):

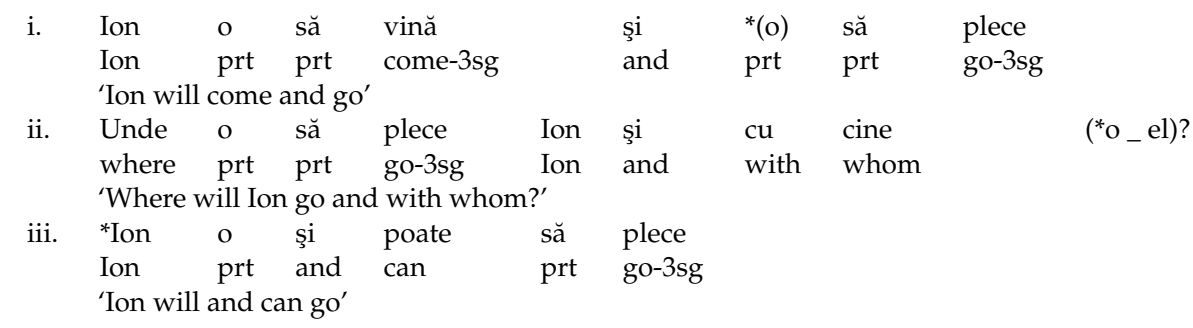

The point made in the present paper is the following: the presence of the subjunctive particle is taken as an indication for a separate clause. However, given the single event interpretation that arises in the structures under consideration, the interpretation is that of a mono-clausal structure (as in restructuring contexts). This predicts that the suggested configuration will have all the properties attested in a single clause, namely a single negator, coordination of identical structure, as in (i), and ellipsis affecting the "big" CP, as in (ii). Note also that the grammatical version of coordination, as in (i), necessarily triggers an interpretation with two separate events. Finally, coordination of the future particle with another modal is excluded on the assumption that the future particle is a clitic. The future particle itself is a reduced form in terms of argument structure as well; the latter is supplied by the clause headed by the subjunctive particle. 
23. a. Hai!

$$
\text { 'C'mon!' }
$$

b. Hai/ haideţi plecaţi!

hai hai.2pl go.2pl.imp

'Go!'

c. Hai să citim.

hai prt read-1pl

'C'mon, let's read.'

d. Hai că este nemaipomenit.

hai that is unbelievable

'It is unbelievable, really.'

As shown in the above examples, hai (or haide) can occur on its own in (23a) and define an utterance which is very similar to an imperative. In (23b), it is followed by an imperative verb with which it may agree in person and number (2nd person plural). In (23c), it is followed by a subjunctive să-clause, while in (23d), it is followed by an indicative (declarative) că-complement. Hill $(2008,2013 b)$ distinguishes two readings for hai/haide: the injunctive and the evaluative (or evidential). In the injunctive reading, hai/haide may occur on its own or with the imperative verb as in (23a) and (23b). The injunctive reading is found with the subjunctive clause as well, as in (23c). In the injunctive reading, hai/haide reinforces the imperative (Greenberg 1996, p. 60). The evaluative/evidential reading, on the other hand, is found with the $c \breve{a}$-clause in (23d).

A very similar pattern is attested in Greek, Albanian and Bulgarian. Consider next the Greek examples below (Roussou 2017):

24. a. Ande!

'C'mon!'

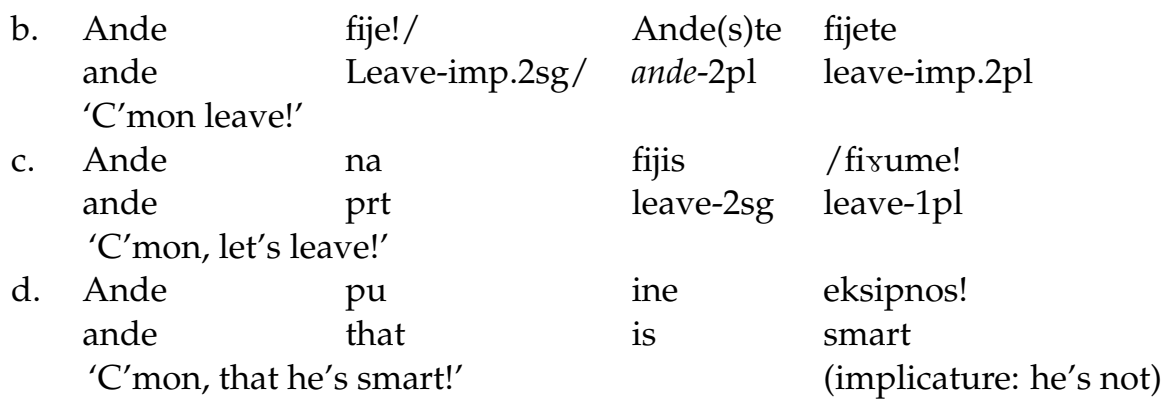

As in Romanian, Greek ande can occur on its own, resembling an imperative in (24a) ("come" or "go"), precede an imperative verb in (24b) with an inflectional plural ending, precede the subjunctive particle $n a$ in $(24 \mathrm{c})$, or embed a pu-clause in (24d). We should point out that $p u$ is a declarative complementizer introducing factive complements and relative clauses, thus differing from the declarative complementizer ot $i$ which can introduce non-factive complements as well (for an overview, see Roussou 2010; see also Bulgarian deto, Krapova 2010). Ande in Greek also yields two basic readings: the injunctive and the evaluative/evidential. When it reinforces an imperative, as in (24b), or a na-clause, as in (24c), it is injunctive; in (24d), it is evaluative. Note though that the reading we obtain in this case does not quite match the Romanian one, since it triggers a negative implicature (i.e., "Of course he is not smart"). Makri (2019) argues, based on similar constructions, that $p u$ in this case is non-factive. It is not clear that the reading is non-factive, to the extent that the presence of ande forces the speaker to evaluate what the hearer holds to be true as being false; we leave this open at present.

We next move to Albanian hajde: ${ }^{6}$

\footnotetext{
6 I am grateful to Brian Joseph and Kostando Baruta for their help with the Albanian data.
} 
25. a. Hajde!

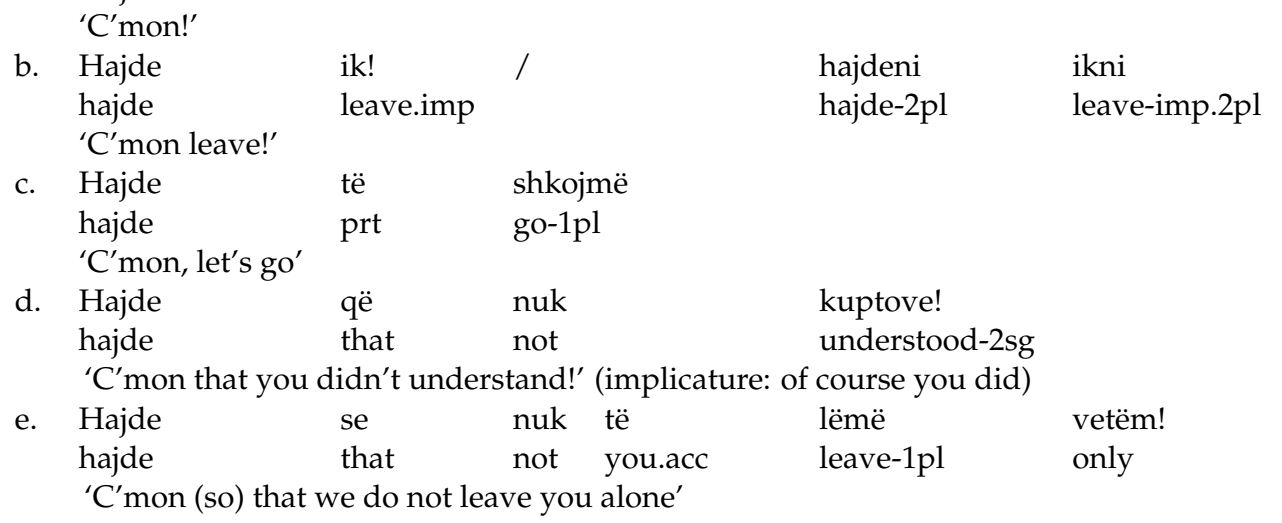

Once again, we find an almost identical distribution. In particular, we find hajde standing on its own as an utterance in (25a), reinforcing an imperative in (25b) with the option of inflecting for plural, i.e., hajde-ni, preceding a subjunctive të-clause in (25c), or taking a that-complement as in (25d) and (25e). Interestingly, the presence of the declarative complementizer $q \ddot{e}$ gives rise to the same reading as Greek $p u$. Note that although që is the complementizer introducing a $t \ddot{e}$-clause, it is also a relativizer, like Greek $p u$. Finally, in (25e), hajde is followed by a se-clause (recall that se is the indicative complementizer); this is similar to Romanian (22d). In the last two cases, we have an evaluative reading, along the lines discussed for Romanian and Greek.

The presentation concludes with Bulgarian xajde or ajde (from Tchizmarova 2005; her translations):

26. a. Xajde/ajde!

$\begin{array}{llllll}\text { 'Let's!' } & & & & \\ \text { ajde } & \text { obadi } & \text { mi } & \text { se sled dvajset minuti } \\ \text { ajde } & \text { call-2sg.imp } & \text { me refl in twenty minutes } \\ \text { 'Could you call me in twenty minutes?' } & & & \\ \text { ajde } & \text { da } & \text { jadem } & & & \\ \text { ajde } & \text { prt } & \text { eat-1pl } & & \\ \text { 'Let's eat' } & & & & \end{array}$

Regarding the above translations, Tchizmarova provides the following clarification in fn. 7: "Xajde itself is translated differently in the examples depending on the context and what might be used in similar utterances in English". Still, we identify a similar distribution to the extent that xajde may stand on its own, as in (26a), or precede an imperative, as in (26b), or a subjunctive $d a$-clause, as in (26c).

The data so far show that the discourse marker "haide" can either have imperative force on its own, or reinforce an imperative or a subjunctive clause, and at least in Romanian, Greek, and Albanian, may also give rise to an evaluative reading when it precedes a "that"complement clause. The data are quite robust in this respect. In the present discussion, we restrict our attention to the above patterns (and do not exhaust the full distribution of "haide") as these seem to involve properties associated with the left periphery. We next turn to their analysis.

\section{2. "Haide" and Force}

Hill (2008, 2013b) and Haegeman and Hill (2013) argue in favor of the "syntacticization of discourse", that is the encoding of discourse properties in syntax. They adopt and adapt the Speech Act shell of Speas and Tenny (2003) which revives Ross' (1970) performative hypothesis. Speas and Tenny argue that the Speech Act shell is predicative, similar to the $\mathrm{vP}$-shell. Unlike the vP-shell whose arguments are the event participants, those of the SA-shell are the discourse participants, namely, the Speaker, the Hearer/Addressee, and the Utterance. 
Hill (2013b), in particular, argues that hai/haide realizes the lower Speech Act position which introduces the Hearer, while the higher Speech Act projection introduces the Speaker, as in (27). In the structure below, SAsP stands for Speech Act Speaker, and SAhP for Speech Act Hearer.

\section{7. [SAsP SAs [SAhP hai] [FORCEP Utterance/că ... ]]}

Hill excludes an analysis that takes hai and its inflected versions, like haideţi (or haidem with 1st person plural inflection) to be a verbal element. She takes this agreement to be the result of agreement with the main verb. Miyagawa (2020) argues that this is an instance of "allocutive" agreement. Roussou (2017), on the other hand, building on the morphological similarities between Greek ande and imperatives, argues that ande is a predicative element realizing a SA head with reduced inflectional and argument properties. The latter are taken to be restricted to the discourse participants and more precisely the hearer/addressee.

Recall from the presentation of the data in Section 3.1 that one of the functions of "haide" is the reinforcement of the imperative verb. The same reading extends to the subjunctive clause, which in the languages under consideration may also function as a "surrogate" imperative. In our discussion of the subjunctive particles in Section 2, we argued that they are externalizations of a D (a nominal) feature in the left periphery and that they function as linkers. As such, subjunctive particles turn the proposition into a predicate, subject to a modal interpretation in matrix clauses, in the scope of the Force head. Force was taken to be a scope position, which could be externalized by the verb. Rivero (1994) argues that the imperative verb in Greek and Romanian occurs in a position above I/T, and in particular C, given that we have enclisis instead of proclisis, as in (28) (the Romanian example from Rivero p. 105): ${ }^{7}$

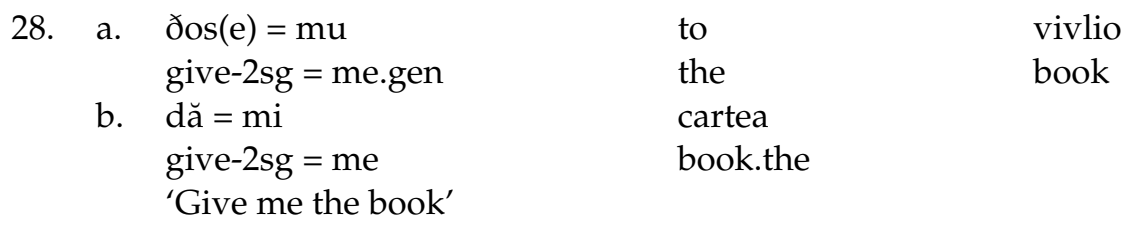

In the context of the articulated structure we argued for in Section 2.2, this position can be identified with Force, a scope position of V. In principle, Force can be externalized by the main verb, or by another verbal element which forms a chain with the main verb. Recall that this latter option was argued to hold for the externalization of $\mathrm{M}$ by the future particle.

Bearing the above in mind, let us go back to the two main constructions with "haide", i.e., with the imperative verb or the subjunctive clause. Let us start with the latter. One option is for "haide" to behave like an imperative verb and externalize Force, as in (28):

\section{8. [Force 'haide' [D(Lkr) Subjunctive particle [ ... [I/T}

The obvious question is what "haide" shares with imperatives. As we saw above, it can reinforce an imperative or a "surrogate" imperative. Furthermore, at least in Romanian, Albanian and Greek, it can take a 2nd person plural affix. Note that in Greek, imperatives have a different inflectional paradigm from indicatives. In particular, $-e$ is the affix for 2 nd person singular in the imperative mood and -ete for the 2 nd person plural. The agreement affix of the imperative maps on a discourse participant, and in particular, the Addressee, thus differing from the agreement affix of the indicative which is the externalization of the EPP subject. In Zanuttini's (2008, p. 185) words, “The interpretation of imperative clauses

\footnotetext{
The Balkan languages discussed here do not behave alike with respect to imperatives. For example, Greek and Albanian have a specialized negator and do not allow for negated imperatives; in the latter case, they revert to the indicative form of the verb. Romanian also exhibits a "surrogate" imperative in the presence of negation, while Bulgarian (and Macedonian) allows for negated imperatives. Furthermore, Bulgarian and Macedonian allow for object clitics to precede or follow the imperative verb (Tomić-Mišeska 1999). It is possible then to assume that in Bulgarian and Macedonian, the verb in the imperative clause is not in Force (or does not have to be in Force). On the other hand, this latter option has been argued for Romanian as well (Isac 2015) based on the distribution of Focus and Topic (preceding the imperative verb). The comparative picture supports the view that the imperative verb may occupy different V-related positions in the left periphery. This is consistent with the view being put forward here to the extent that these are scope positions of the verb.
} 
typically involves an individual that corresponds to the addressee in the given context, or a set of individuals that coincides or overlaps with the set of addressees". At least in Greek then, ande can be taken as the equivalent of an imperative (modulo, the - $e$ ending), further allowing for the plural form. In other words, the two forms of ande may morphologically resemble imperatives.

If the above reasoning is on the right path, the association of "haide" with a discourse participant can be derived from its imperative force. In this respect, the structure in (28) becomes relevant for those cases where an imperative form of the verb qualifies as a discourse marker. This is illustrated with the imperative kita "look" in Greek below:

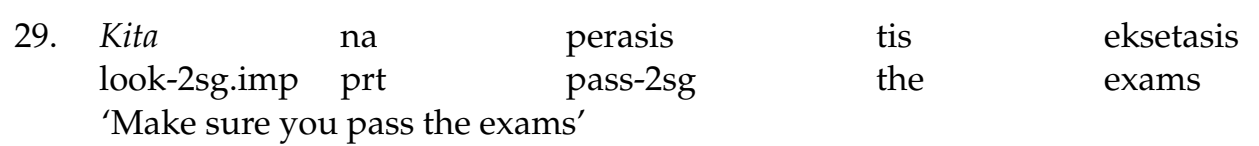

The imperative kita reinforces the surrogate imperative, that is the na-clause. Other perception verbs may be used, such as aku "listen" (on perception verbs as discourse markers in the imperative, see Fagard 2010 and Cardinaletti 2015).

Consider next the case where "haide" is followed by an imperative. If "haide" is in Force, the question is what position the main verb occupies, bearing in mind its imperative form. A sequence of two verbs which share morphosyntactic features in the same clause is attested independently. A well-known case is the "go get" construction in English, as in (30a) below (from Jaeggli and Hyams 1993, p. 313), also found in Greek (30b):

30. a. Come talk to me/Go climb a rock

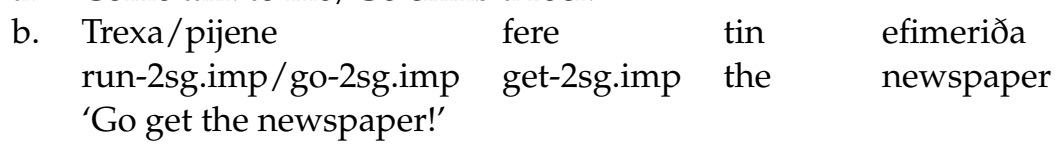

Jaeggli and Hyams (1993) argue that the verbs come and go in these constructions are aspectual markers, subject to inflectional restrictions (cf. *John goes get the newspaper) which assign a secondary $\theta$-role to the subject of the main verb (for a more recent view, see Bjorkman (2016) who accounts for these restrictions in terms of Distributed Morphology). Joseph (1990) discusses these verbs in relation to Greek and points out that they are restricted to imperative contexts. He entertains the idea that Greek (30b) is a serial verb construction, although, as he admits, it differs from serial verbs in that it is restricted to imperatives. He further notes that this pattern is also attested with ande as well as with the preposition $j a$ "for", as in (31):

31. Ja fere tin efimeriða
for get-2sg.imp the newspaper
'Go get the newspaper!'

The above discussion shows that what we observe with "haide" + imperative V may arise with other lexical items as well (e.g., motion verbs).

Going back to "haide" and bearing in mind that we are dealing with a more general phenomenon. One possible way to proceed is to assume that the "haide- $V$ " sequence is a complex head (see the "go get" analysis of Bjorkman 2016). In other words, "haide" is like a modifier to the imperative verb, the latter being the main externalization of Force, as in (32a), replicated in (32b) for the V1-V2 sequence we saw in (30b):

$$
\begin{aligned}
& \text { 32. a. [Force ['haide' } \left.\left.-\mathrm{V} 2_{\text {imperative }}\right]\right] \\
& \text { b. [Force } \left.\left[\mathrm{V} 1_{\text {imperative }}-\mathrm{V} 2_{\text {imperative }}\right]\right]
\end{aligned}
$$

At this point, we need to clarify the notion of "complex head" in syntactic terms. First, note that there is (strict) adjacency between "haide" and the imperative verb; the same holds for the sequence of imperative verbs in (30b). "Haide" may combine with other discourse markers of this sort, as argued by Hill (2013b). In particular, Hill gives examples like (33a-b) (p. 173), and an anonymous reviewer suggested the example in (33c) with the imperative verb (uite, $i a$, and $n a$ are also discourse particles): 


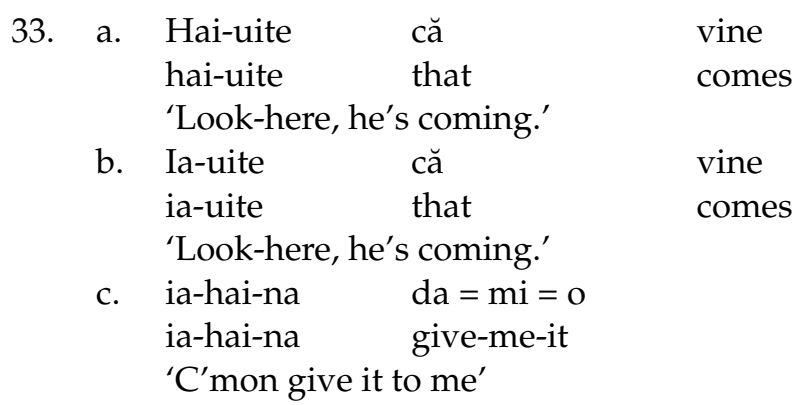

Discourse particles have a fixed order and their complex qualifies as a single prosodic unit. According to Hill (p. 174), "the first particle is a functional item in the projection of the second particle, more in the ways of a complex tense with verbs". Despite differences in implementation, the "restructuring" approach of Hill is quite close to the configuration given in (32). Note that in Greek as well, ande can modify a sequence of imperative verbs, like ande pijene fere tin efimeriða " $\mathrm{c}$ 'mon go get the newspaper". Ande modifies the pijene fere sequence, while pijene modifies (enhances) the main verb fere (the command after all is "bring the newspaper").

Bearing the above in mind, let us elaborate on (32). The crucial notion here is that of a "sequence". Chomsky (2020) argues that sequences are derived by Pair Merge. For example, in a sentence like I met someone young, happy, eager to go to college, tired of wasting his time, there is a sequence of adjectives modifying the noun someone. Each adjective is in a predicative relation with the noun it modifies: "every member of this coordinated construction, every individual member of it is individually predicated of what it links to". (p. 50). The sequence involves links like $\langle$ young, someone $>,<$ happy, someone $>$, etc. The elements that function as adjuncts are invisible to labeling. In Chomsky's terms (p. 50), “So we have a sequence of elements that looks like this, with links $\mathrm{L}_{\mathrm{i}}$.

$<\mathrm{CONJ},<\mathrm{S}_{1}, \mathrm{~L}_{1}>, \ldots,<\mathrm{S}_{n}, \mathrm{~L}_{n}>>^{\prime \prime}$

In Pair Merge, each of the elements in the pair is inaccessible to other operations. Interestingly, Chomsky suggests that Pair Merge may be involved with causative (and perception) verbs, in sentences like They let/made the man walk down the street. At least with respect to causatives, the idea is that the verb is like a causative morpheme, which in English is spelled out as a separate word (and not an affix). Irrespectively of spelling out options, the formation is a sequence, i.e., <let, walk> (or <make, walk>) under Pair Merge.

Given the above discussion, let us now go back to the structure in (32). Recall that there is and adjacency requirement between "haide" and the imperative verb (or between the discourse particles and the imperative verb). Recall also that "haide" modifies the imperative verb (the injunctive reading). Following Chomsky (2020), we can argue that "haide" and the verb are pair-merged, i.e., <haide, $V_{i m p}>$. This is an elementary sequence, consisting of a single link. If there is another discourse particle, the sequence will have two links, and so on. The same approach can extend to the sequence of two imperative verbs, i.e., <pijene, fere $>$. It is further possible to have ande modifying this sequence, in which case, we would have two links, i.e., <ande, pijene $>,<$ ande, fere $>$. What merges in Force is the corresponding sequence created by Pair Merge. The modifying elements are invisible to labeling. Thus, the notion of the "complex head" invoked in (32) is now understood as a sequence, indicated with angle brackets:

$$
\begin{aligned}
& 32^{\prime} . \text { a. }\left[\text { Force }<\text { haide }^{\prime}-\mathrm{V} 2_{\text {imperative }}>\right.\text { ] } \\
& \text { b. }\left[\text { Force }<\mathrm{V} 1_{\text {imperative }}-\mathrm{V} 2_{\text {imperative }}>\right.\text { ] }
\end{aligned}
$$

The above does not involve notions like complex head, while it accounts for the cooccurrence of particles with a single verb (and of sequences of verbs).

Before we conclude our discussion, we need to discuss the third case attested in Romanian, Albanian and Greek, where "haide" embeds a clausal complement. Maintaining the view that "haide" externalizes the Force head, and consistent with the view that 
complementizers are not externalizations of Force (see the discussion in Section 3), the structure is as follows:

\section{4. [Force 'haide' [că/pu/\{se, qü\} [ . . [I/T ...}

According to (34), Romanian haide embeds a că-complement, Greek ande embeds a pucomplement, while Albanian hajde takes a se- or a që-complement. Following Hill (2013b), the constructions in (34) exhibit an evaluative reading. In other words, the readings that arise depend not only on "haide" but also on the type of constituent it embeds. Just to complete the similarities with imperative verbs, note that, at least in Greek, the verb sopeno "shut up/be silent" takes a pu-clause and also assigns an evaluative reading in its imperative form only, very much like ande (see Makri 2019, p. 195). This is illustrated in (35):

$\begin{array}{llll}\text { 35. Sopa } & \text { pu } \theta \text { a pao exo } & \text { eki } \\ \text { Shut.up-2sg.imp that prt go-1sg I } & \text { there } \\ \text { 'I won't go there!' [Lit. 'shut up that I go there'] } & \end{array}$

Therefore, once again we have a pattern which is not restricted to "haide".

To summarize the discussion, in this section, we considered the discourse marker "haide", based on data from Romanian, Greek, Albanian and Bulgarian. The analysis considered the similarities "haide" has with imperatives. Its discourse properties derive from the complement it takes and the anchoring to the discourse participants. Consistent with current approaches, the present account argues that "haide" enters the syntactic derivation and externalizes formal features associated with force. Although its presence in the Balkan languages is taken to be due to lexical borrowing (albeit with no recorded history), its morphosyntactic accommodation follows the structural properties of the recipient grammars. In this respect, it is consistent with the Thomason and Kaufman (1988, p. 37) definition of borrowing: "Borrowing is the incorporation of foreign features into a group's native language by speakers of that language: the native language is maintained but is changed by the addition of the incorporated features"..

\section{From E-Language to I-Language: Some Concluding Remarks}

In the present paper, we considered two sets of data: the first involves modal particles, while the second involves the discourse marker "haide". Modal particles split into future and subjunctive markers. It was argued that future particles are V-related elements and as such, they externalize the $\mathrm{M}$ position of the main verb. On the other hand, subjunctive particles were argued to relate to nominal features (the EPP) associated with the verb, functioning as linkers ( $\lambda$-operators). We showed that based on the different features they externalize, they merge in different positions along the left periphery of the clause. This gave rise to an elaborate left periphery, allowing for finer distinctions among grammars, consistent with microparametric variation. The analysis of "haide" was also set within this articulated structure. We entertained the idea that "haide" externalizes features of the Force head, modifying the imperative verb or the subjunctive clause which functions as a "surrogate" imperative. On the other hand, the embedding of a declarative clause gives rise to an evaluative reading. The elaborate left periphery argued for in Section 3 was extended to accommodate the analysis of "haide" without postulating a Speech Act shell.

The way we proceeded was from E-language to I-language. To be more precise, first we considered the features of the two sets of particles and then moved onto the articulation of the left periphery. This allowed us to pay closer attention to the similarities attested in the externalizations provided in the languages under consideration; for example, the similarities among the future particles as verbal "residues", the option of embedding a finite form of the verb or a subjunctive clause, their positioning in relation to clitics, etc. A similar stand was taken towards the subjunctive particles, their relation (or identity)

8 For a discussion of "borrowing" in a pragmatics and psycholinguistic perspective, see Treffers-Daller (2010). 
with other elements (articles, demonstratives, conjunctions) in the grammar, and their distribution in matrix and complement clauses. Particularly with respect to the subjunctive particle, we showed that the term "subjunctive" can only describe some of its functions, with special reference to the matrix clause. However, it can be misleading with respect to its categorial features; the latter are formal features part of the I-language.

The present discussion was based on the background assumption that the languages under consideration exhibit "structural convergence" (or what Sims and Joseph (2019) call "surface similarities"), historically attributed to areal characteristics under language contact. Regarding the sociolinguistic setting in the 19th century Balkan area, Lindstedt (2000, p. 239) observes the following "Because of population mixture-as well as such specifically Balkan phenomena as transhumance-speakers of different languages must often communicate with each other. There is no single lingua franca they could resort to, but different multilingual strategies are adopted. Since speakers of each language have sufficient access to other languages they need in order to communicate, no pidginized varieties arise; individuals acquire various degrees of bilingualism and multilingualism. The multilingual situation gradually leads to structural convergence between the languages, but as languages remain important symbols of group identity, they all retain their distinct lexica". This quotation provides us with the background sociolinguistic context: there are multilingual communities, with no lingua franca nor group identity (so speakers maintain their native language). The last comment in this quotation is also relevant to the current discussion, as it implies that while the varieties spoken may converge in structural terms, the distinct lexica are maintained. From a theoretical perspective, what interests us is what "structural convergence" means from the I-perspective.

Given the above, the aim of the present paper was not to account for how convergence was historically achieved. The aim instead was to elaborate what this convergence means for I-language, i.e., what the various externalizations tell us for the more abstract grammatical properties. To this end, despite maintaining different lexica, the languages under consideration seem to share a fine-grained left periphery. The case of "haide" was also quite revealing in this respect. It is a pan-Balkan characteristic which goes beyond lexical borrowing. Our discussion showed that its morphosyntactic properties are consistent with the features associated with the left periphery.

To conclude, in the present paper, we considered two common features of Balkan languages that include the "modal particles" for the expression of the future and the subjunctive, and the element "haide". It was argued that the distribution of modal particles argues in favor of an articulated left periphery which can accommodate the similarities attested while allowing for microvariation as well. While modal particles participate in grammatical relations, discourse particles, despite their expressive content, are also items that enter narrow syntax.

Funding: This research received no external funding.

Institutional Review Board Statement: Not applicable.

Informed Consent Statement: Not applicable.

Data Availability Statement: The data presented in this study are available in the sources cited in the text and footnotes. All other data which have no cited sources are created by me or suggested by the reviewers as acknowledged.

Acknowledgments: I would like to thank the three anonymous reviewers for their extremely useful and constructive comments, as well as the audience of the SLE 2020 Workshop on "Contact and the Language Faculty" for the discussion.

Conflicts of Interest: The author declares no conflict of interest. 


\section{References}

Bjorkman, Bronwyn. 2016. Go get, come see. Motion verbs, morphological restrictions, and syncretism. Natural Language and Linguistic Theory 34: 53-91. [CrossRef]

Camaj, Martin. 1984. Albanian Grammar with Exercises, Chrestomathy and Glossaries. Collaborated and translated by Leonard Fox. Wiesbaden: Otto Harrasowitz.

Cardinaletti, Anna. 2015. Italian verb-based discourse particles in a comparative perspective. In Discourse-oriented Syntax. Edited by Josef Bayer, Roland Hinterhölzl and Andreas Trotzke. Amsterdam: John Benjamins, pp. 71-91. [CrossRef]

Chomsky, Noam. 2020. The UCLA Lectures. Ms. Available online: https:/ /ling.auf.net/lingbuzz/005485 (accessed on 6 April 2021).

Christidis, Anastasios Ph. 1985. To $\delta \varepsilon\llcorner\kappa \tau \iota k o ́ ~ ' v \alpha$ ' [The deictic 'na']. Studies in Greek Linguistics 6: 221-41.

Dobrovie-Sorin, Carmen. 1994. The Syntax of Romanian. Berlin: Walter De Gruyter.

Dobrovie-Sorin, Carmen. 2001. Head-to-head merge in Balkan subjunctives and locality. In Comparative Syntax of Balkan Languages. Edited by María Luisa Rivero and Angela Ralli. New York: Oxford University Press, pp. 44-73.

Fagard, Benjamin. 2010. E vidha, ola ... : Imperatives as discourse markers and grammaticalization paths in Romance. A diachronic corpus study. Languages in Contrast 10: 245-67. [CrossRef]

Giorgi, Alessandra. 2010. About the Speaker. Towards a Syntax of Indexicality. Oxford: Oxford University Press.

Greenberg, Robert D. 1996. The Balkan Slavic appellative. München, Newcastle: Lincom Europa.

Haegeman, Liliane, and Virginia Hill. 2013. The syntacticization of discourse. In Syntax and its Limits. Edited by Rafaella Folli, Christian Sevdali and Robert Truswell. Oxford: Oxford University Press, pp. 370-90. [CrossRef]

Hill, Virginia. 2008. Pragmatic markers as syntactic heads: A case study from Romanian. In Selected Papers form the 2006 Cyprus Syntaxfest. Edited by Kleanthes Grohmann and Phoevos Panagiotidis. Newcaslte upon Tyne: Cambridge Scholars Publishing, pp. 237-65.

Hill, Virginia. 2013a. The emergence of the Romanian subjunctive. The Linguistic Review 30: 1-37. [CrossRef]

Hill, Virginia. 2013b. Vocatives. How Syntax Meets Pragmatics [with the contribution of Melita Stavrou]. Leiden: Brill.

Hill, Virginia, and Olga Mišeska-Tomić. 2009. A typology of subjunctive complements in Balkan languages. Bucharest Working Papers in Linguistics (BWPL) XI: 197-208.

Isac, Daniela. 2015. The Morphosyntax of Imperatives. Oxford: Oxford University Press.

Jaeggli, Osvaldo A., and Nina M. Hyams. 1993. On the independence and interdependence of syntactic and morphological properties: English aspectual come and go. Natural Language and Linguistic Theory 11: 313-46. [CrossRef]

Joseph, Brian D. 1983. The Synchrony and Diachrony of the Balkan Infinitive. Cambridge: Cambridge University Press.

Joseph, Brian D. 1990. On arguing for serial verbs (with special reference to Modern Greek). In When Verbs Collide: Papers from the Ohio State Mini-Conference on Serial Verbs. OSU Working Papers in Linguistics 39. Edited by Brian D. Joseph and Arnold Zwicky. Columbus: Department of Linguistics, Ohio State University, pp. 77-90.

Joseph, Brian D. 2001. Is Balkan comparative syntax possible? In Comparative Syntax of Balkan Languages. Edited by María Luisa Rivero and Angela Ralli. New York: Oxford University Press, pp. 17-43.

Krapova, Iliana. 2010. Bulgarian relative and factive clauses with an invariant complementizer. Lingua 120: 1240-72. [CrossRef]

Landau, Idan. 2013. Control in Generative Grammar. A Research Companion. Cambridge: Cambridge University Press.

Lindstedt, Jouko. 2010. Mood in Bulgarian and Macedonian. In Mood in the Languages of Europe. Edited by Björn Rothstein and Rolf Thieroff. Amsterdam: John Benjamins, pp. 409-22. [CrossRef]

Lindstedt, Jouko. 2000. Linguistic Balkanization: Contact-induced change by mutual reinforcement. In Languages in Contact (Studies in Slavic and General Linguistics 28). Edited by Dicky Gilbers, John Nerbonne and Jos Schaeken. Amsterdam, Atlanta: Rodopi, pp. 231-46. Available online: https://www.jstor.org/stable/40997168 (accessed on 1 February 2021).

Makri, Maria Margarita. 2019. Non-factive pu? 13th International Conference on Greek Linguistics (ICGL13). Edited by Maria Chondrogianni, Simon Courtenage, Geoffrey Horrocks, Amalia Arvaniti and Ianthi Tsimpli. pp. 193-201. Available online: http:/ /icgl13.westminster.ac.uk/ (accessed on 26 January 2021).

Manzini, M. Rita, and Anna Roussou. 2020. Recategorizing C. Ms. University of Florence and University of Patras. Available online: https:/ /ling.auf.net/lingbuzz/005771 (accessed on 2 December 2020).

Manzini, M. Rita, and Leonardo M. Savoia. 2011. Grammatical Categories. Cambridge: Cambridge University Press.

Manzini, M. Rita, and Leonardo M. Savoia. 2018. The Morphosyntax of Albanian and Aromanian Varieties. Berlin, Boston: Mouton de Gruyter.

Markopoulos, Theodore. 2009. The Future in Greek: From Ancient to Medieval. Oxford: Oxford University Press.

Maschler, Yael, and Deborah Schiffrin. 2015. Discourse markers. Language, meaning, and context. In The Handbook of Discourse Analysis. Edited by Deborah Tannen, Heidi Hamilton and Deborah Schiffrin. Hoboken: John Wiley \& Sons, pp. 189-221.

Miyagawa, Shigeru. 2020. Syntax in the Treetops, Ms. September 2020 Version; Available online: http:/ /www.shigerumiyagawa.com/ (accessed on 1 March 2021).

Nicholas, Nick. 2010. A Turkish Etymology for Both $\alpha$ and $\sigma \iota \chi \tau i \rho$. Blog: Hellenisteukontos. Available online: http://hellenisteukontos. blogspot.gr/2010/06/turkish-etymology-for-both-and.html (accessed on 4 February 2021).

Nicolescu, Dana. 2011. The grammaticalization of the future tense forms in 16th century Romanian. Revue Roumaine de Linguistique LVI: 421-40.

Philippaki-Warburton, Irene. 1998. Functional categories and Modern Greek syntax. The Linguistic Review 15: 159-86. [CrossRef] 
Rivero, María Luisa. 1994. Clause structure and V-movement in the languages of the Balkans. Natural Language and Linguistic Theory 12: 63-120. [CrossRef]

Rivero, María Luisa. 2005. Topics in Bulgarian morphology and syntax: A minimalist perspective. Lingua 115: 1083-128. [CrossRef]

Rivero, María Luisa, and Angela Ralli. 2001. Introduction. In Comparative Syntax of Balkan Languages. Edited by María Luisa Rivero and Angela Ralli. New York: Oxford University Press, pp. 3-16.

Rizzi, Luigi. 1997. The fine structure of the left periphery. In Elements of Grammar. Edited by Liliane Haegeman. Dordrecht: Kluwer, pp. 281-337.

Rizzi, Luigi, and Guiliano Bocci. 2017. Left periphery of the clause. Preliminary illustrated for Italian. In The Wiley Blackwell Companion to Syntax, 2nd ed. Edited by Martin Everaert and Henk C. van Riemsdjik. Oxford: Wiley-Blackwell. [CrossRef]

Roberts, Ian, and Anna Roussou. 2003. Syntactic Change: A Minimalist Approach to Grammaticalization. Cambridge: Cambridge University Press.

Ross, John R. 1970. On declarative sentences. In Readings in English Transformational Grammar. Edited by Roderick A. Jacobs and Peter S. Rosenbaum. Waltham: Ginn \& Co, pp. 222-72.

Roussou, Anna. 2009. In the mood for control. Lingua 119: 1811-36. [CrossRef]

Roussou, Anna. 2010. Selecting complementizers. Lingua 120: 582-603. [CrossRef]

Roussou, Anna. 2015. Is particle a (unified) category? In Discourse-Oriented Syntax. Edited by Josef Bayer, Roland Hinterhölzl and Andreas Trotzke. Amsterdam: John Benjamins, pp. 121-58. [CrossRef]

Roussou, Anna. 2017. Expanding on the left. Linguistica Brunensia 65: 7-20.

Sims, Andrea, and Brian Joseph. 2019. Morphology versus syntax in the Balkan verbal complex. In Balkan Syntax and (Universal) Principles of Grammar. Edited by Brian Joseph and Iliyana Krapova. Berlin: Mouton/de Gruyter, pp. 99-150. [CrossRef]

Sonnenhauser, Barbara, and Paul Widmer. 2019. Prefixal articles across domains. Syntactic licensing in Albanian. Folia Linguistica 53: 25-49. [CrossRef]

Speas, Margaret, and Carol Tenny. 2003. Configurational properties of point-of-view roles. In Asymmetry in Grammar. Edited by Anna-Maria di Sciullo. Amsterdam: John Benjamins, pp. 315-44.

Thomason, Sarah Grey, and Terrence Kaufman. 1988. Language Contact, Creolization and Genetic Linguistics. Berkeley: University of California Press. [CrossRef]

Todorović, Natasa. 2012. The Indicative and Subjunctive da-Complements in Serbian. A Syntactic-Semantic Approach. Ph.D. thesis, University of Illiois at Chicago, Chicago, IL, USA.

Tomić-Mišeska, Olga. 1999. Negation and imperatives. Catalan Working Papers in Linguistics (CatWPL) 7: 191-206.

Tomić-Mišeska, Olga. 2004a. The Balkan Sprachbund properties. In Balkan Syntax and Semantics. Edited by Olga Mišeska-Tomić. Amsterdam: John Benjamins, pp. 1-59.

Tomić-Mišeska, Olga. 2004b. The syntax of the Balkan Slavic future tenses. Lingua 114: 517-42. [CrossRef]

Tomić-Mišeska, Olga. 2006. Balkan Sprachbund Morphosyntactic Features. Dordrecht: Springer.

Treffers-Daller, Jeanine. 2010. Borrowing. In Variation and Change: Pragmatic Perspectives. Handbook of Pragmatics Highlights 6. Edited by Mirjam Fried, Jan-Ola Östman and Jef Verschueren. Amsterdam, Philadelphia: John Benjamins, pp. 17-35. Available online: http:/ / centaur.reading.ac.uk/20665/ (accessed on 26 January 2021).

Tsangalidis, Anastasios. 1999. Will and Tha: A Comparative Study of the Category Future. Thessaloniki: University Studio Press.

Tchizmarova, Ivelina K. 2005. Hedging functions of the Bulgarian discourse marker xajde. Journal of Pragmatics 37: 1143-63. [CrossRef]

Turano, Guiseppina. 2000. On clitics and negation in Albanian. Rivista di Grammatica Generativa (RGG) 25: 81-177.

Turano, Guiseppina. 2017. Modal particles in Albanian subjunctive, infinitive and supine constructions: Presence vs. absence of clitic climbing. Quaderni di Linguistica e Studi Orientali 3: 61-86. [CrossRef]

Zanuttini, Rafaella. 2008. Encoding the addressee in the syntax: Evidence from English imperative subjects. Natural Language and Linguistic Theory 26: 185-218. [CrossRef] 